\title{
LÓGICA FUZZY NA ANÁLISE ESPACIAL DOS TEORES DE K E S NO TECIDO FOLIAR DO MAMOEIRO
}

\author{
Abel Souza da Fonseca ${ }^{1}$ \\ Mariana Lima de Jesus ${ }^{2}$ \\ Julião Soares de Souza Lima ${ }^{3}$
}

Resumo: Objetivou-se com este trabalho utilizar lógica fuzzy para mapear os graus de pertinência do $K$ e do $S$ considerando a variabilidade espacial de cada nutriente avaliado e o conjunto dos teores ideias. $O$ estudo foi realizado em lavoura comercial de mamão, no norte do Espírito Santo, onde forma coletadas folhas recém-maduras em pontos georreferenciados. Foram determinados os teores foliares de $K$ e $S$. Definida a dependência espacial foram confeccionados mapas temáticos por meio da krigagem ordinária. À partir dos mapas, determinou-se o universo de discurso de cada nutriente, seguido da construção dos conjuntos fuzzy de entrada, por meio da função trapezoidal. Com os mapas dos teores foliares realizou-se a classificação fuzzy. Os graus de pertinência para K representam os teores foliares abaixo do recomendado pela literatura. O S encontrado no tecido foliar apresentou se encontarm com mais pertinencia na faixa dos teores ideais.

Palavras-chave: Lógica difusa; Geoestatística; Análise foliar; Carica papaya.

\footnotetext{
${ }^{1}$ Doutorando em Produção Vegetal/Centro de Ciências Agrárias e Engenharias/Universidade Federal do Espírito Santo, Brasil. E-mail: abelsouzafonseca@gmail.com.

2 Centro de Ciências Agrárias e Engenharias/Universidade Federal do Espírito Santo, Brasil. E-mail: marianaldejesus@gmail.com.

3 Departamento de Engenharia Rural-Centro de Ciências Agrárias e Engenharias/Universidade Federal do Espírito Santo, Brasil. E-mail: limajss@yahoo.com.br.
} 